Review

\title{
Analysis of phytosterols in foods
}

\author{
M.J. Lagarda, G. García-Llatas, R. Farré* \\ Nutrition and Food Chemistry, Faculty of Pharmacy, University of Valencia, Burjassot, Spain \\ Received 11 January 2006; received in revised form 21 February 2006; accepted 22 February 2006 \\ Available online 18 April 2006
}

\begin{abstract}
Phytosterols are bioactive compounds, one of their most studied and outstanding properties being their cholesterol-lowering activity. This explains the growing interest in the phytosterol contents of foods as either intrinsic or added components. The different steps (extraction, saponification, clean up, chromatographic determination) of plant sterol determination are reviewed, and emphasis is placed on the methods used to assay different phytosterols in food.
\end{abstract}

(C) 2006 Elsevier B.V. All rights reserved.

Keywords: Phytosterols; Food; Diet; Gas chromatography; Liquid chromatography

\section{Contents}

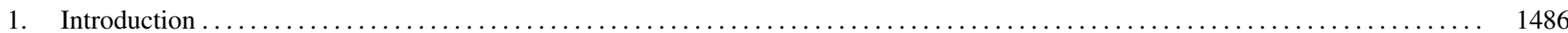

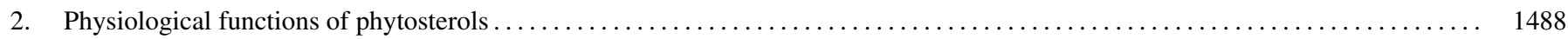

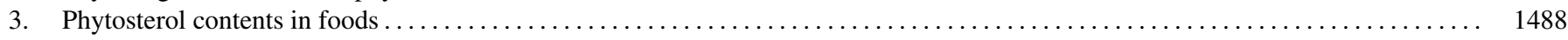

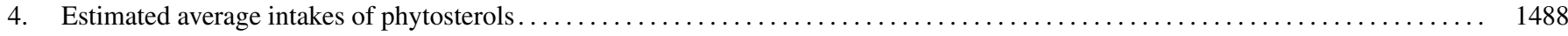

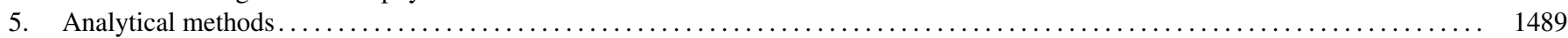

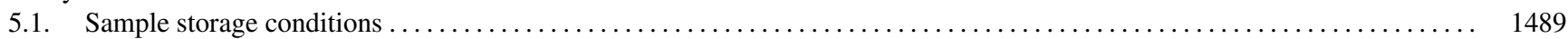

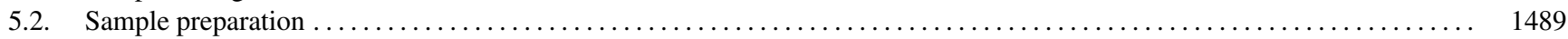

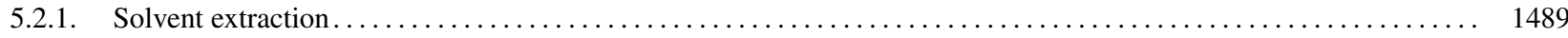

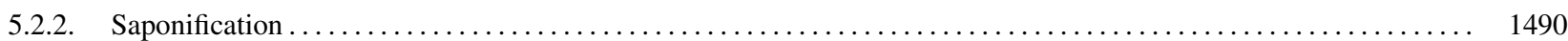

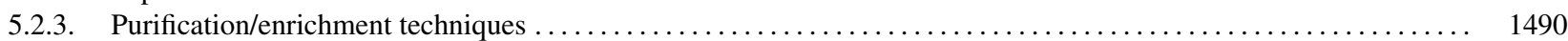

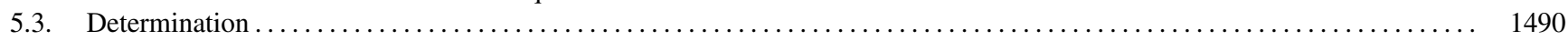

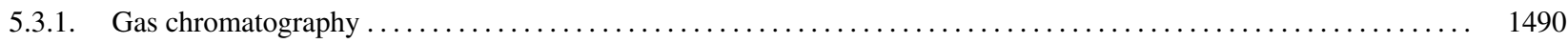

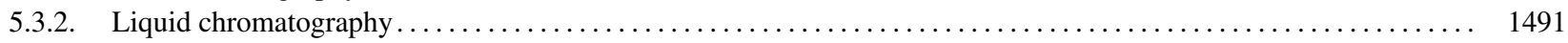

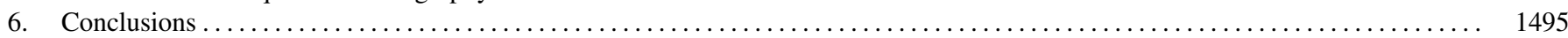

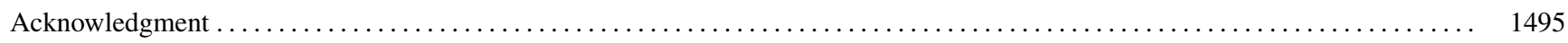

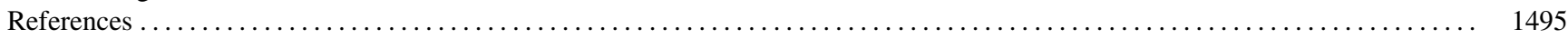

\section{Introduction}

Plant sterols (phytosterols) are bioactive components of all vegetable foods. They are 28- or 29-carbon alcohols and resemble cholesterol in vertebrates in terms of both function (stabilization of phospholipid bilayers in plant cell membranes) and

\footnotetext{
* Corresponding author. Tel.: +34 963544950; fax: +34 963544954 .

E-mail address: rosaura.farre@uv.es (R. Farré).
}

structure (steroid nucleus, 3 $\beta$-hydroxyl group, 5, 6 double bond). Phytosterols contain an extra methyl or ethyl group, or double bond; most phytosterol side chains contain 9-10 carbon atoms, instead of 8 as found in cholesterol. Phytosterols have been classified as 4-demethylsterols of the cholestane series, all of which have double bonds at the C-5 position of the ring [1-3].

In plants, more than 200 different types of phytosterols have been reported the most abundant being $\beta$-sitosterol (24$\alpha$-ethylcholesterol), campesterol (24- $\alpha$-methylcholesterol) and 
<smiles>CC[C@H](CC[C@H](C)[C@H]1CC[C@@H]2[C@@H]3CC=C4CC(O)CC[C@]4(C)[C@@H]3CC[C@]12C)C(C)C</smiles>

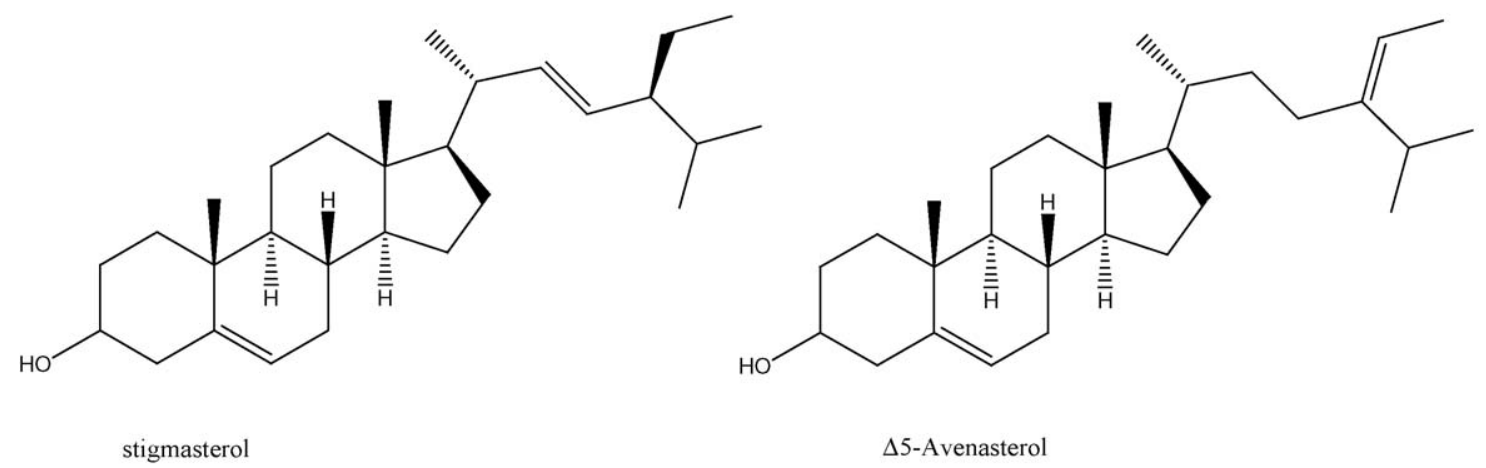<smiles>CC(C)[C@H](C)/C=C/[C@H](C)[C@H]1CC[C@]2(C)C3=CCC4CC(O)CC[C@]4(C)[C@]3(C)CC[C@]12C</smiles>

Fig. 1. Structures of the most commonly phytosterols found in food.

stigmasterol ( $\Delta^{22}, 24-\alpha$-ethylcholesterol). Ergosterol $\Delta^{7,22}, 24$ $\alpha$-methylcholesterol is the principal sterol of yeast and is found in corn, cotton seed, peanut and linseed oils [3]. Structures of the most commonly phytosterols found in food are included in Fig. 1.

In nature, sterols can be found as free sterols or as four types of conjugates in which the $3 \beta$-hydroxyl group is esterified to a fatty acid or a hydroxycinnamic acid, or glycosylated with a hexose (usually glucose) or a 6-fatty acyl hexose. Glycosides are the most common form found in cereals [2].

Phytostanols, a fully saturated subgroup of phytosterols, are intrinsic constituents of cereals (corn, wheat, rye and rice), fruits and vegetables, but their concentrations are generally lower than those of unsaturated plant sterols $[4,5]$.

Phytosterol potency in decreasing serum low-density lipoprotein (LDL) cholesterol levels and thus in protecting against cardiovascular diseases, has led to the development of functional foods enriched with plant sterols.
In 1999, a panel of independent scientists in the United States concluded that plant sterol esters can be Generally Recognized as Safe (GRAS) for use as an ingredient in vegetable oil spreads at a level up to $13.3 \%$ by weight. The United States FDA acknowledged the GRAS notification for the intended conditions of use [6]. In Europe, the Scientific Committee on Food approved the use of phytosterol esters in yellow spreadable fats at a maximum level of $8 \%$ of free sterols in 2000 , after a thorough review of the safety of phytosterols, phytostanols and their esters [7]. More recently, the European Union has issued a commission regulation, EC 608/2004 of 31 March 2004, concerning the labeling of foods and food ingredients with added phytosterols, phytosteryl esters, phytostanols and/or phytostanyl ester [8].

At present, several functional food product types such as spreadable fats, yoghurts and milk, with free phytosterols or phytosteryl fatty acid esters or phytostanyl fatty acid esters added at high levels, are available in the market—especially in several European countries [5]. 


\section{Physiological functions of phytosterols}

Initially, it was shown that soybean sterols could inhibit the increases in plasma and liver cholesterol normally seen in cholesterol-fed chicks, and also reduce the severity of atherosclerotic lesions [9-11]. Contrary to popular belief, the use of phytosterols for lowering serum cholesterol levels is not new. For instance, $\beta$-sitosterol has been used since the 1950s as a supplement and as a drug for lowering serum cholesterol levels in hypercholesterolemic individuals [12]. Since then, several clinical studies have been made on the effect upon blood lipids of 4-demethyl plant sterols or stanols, either in their free or esterified form. These compounds reduce total cholesterol and LDL-cholesterol levels through a reduction in cholesterol absorption. Properly solubilized free sterols and esterified sterols possess similar cholesterol-lowering activity [13-16].

Phytosterols and phytostanols inhibit the uptake of dietary and endogenously produced cholesterol from the gut. The exact mechanism by which this occurs is not fully understood, though several theories have been proposed. One theory suggests that in the intestine, cholesterol already marginally soluble is precipitated into a non-absorbable state by the presence of added phytosterols and stanols. A second theory is based on the fact that cholesterol must enter bile salt and phospholipids containing "mixed micelles" to be absorbed into the bloodstream. Cholesterol is only marginally soluble in these micelles, and is displaced by phytosterols (and stanols) — thereby preventing its absorption [6].

In addition to the mentioned blood cholesterol-lowering effect, phytosterols have shown the following activities in animals: anti-cancer properties (with a beneficial effect upon the inhibition of colon cancer development) [17-20], and antiatherosclerotic [21], anti-inflammatory [22] and anti-oxidative effects [23].

The beneficial effect of phytosterols on serum low density lipoprotein (LDL) cholesterol levels has led to many studies of these compounds in foods and the diet. This increased attention on phytosterol research prompted the development of functional foods with added plant sterols.

\section{Phytosterol contents in foods}

Sterols make up the largest proportion of the unsaponifiable fraction of lipids. Plant fats and oils contain phytosterols as naturally occurring constituents. The most important natural sources of plant sterols in human diets are oils and margarines, although they are also found in a range of seeds, legumes, vegetables and unrefined vegetable oils [4,24-27]. Cereal products are a significant source of plant sterols, their contents, expressed on a fresh weight basis, being higher than in vegetables.

The most abundant sterols in plants are 4-demethylsterols such as sitosterol, campesterol, stigmasterol, $\Delta^{5}$-avenasterol, and $\Delta^{7}$-avenasterol. Sitosterol is the predominant sterol (90\%). Other sterols such as saturated stanols and sterols synthesized earlier in the biosynthesis pathway, such as 4-monomethyl and 4,4-dimethyl sterols, usually appear in lower amounts [28,29].
In foods, plant sterols occur as free sterols, fatty acyl esters, glycosides and fatty acyl glycosides, with substitutions occurring at C3. Accordingly, the total sterol content is defined by the sum of all of them, whereas cholesterol occurs either as free alcoholic sterol or as cholesteryl esters [30-32].

Cereal products are a significant natural plant sterol source (free, esterified and steryl glycosides). The total sterol contents of rye $(95.5 \mathrm{mg} / 100 \mathrm{~g}$, wb), wheat (69.0), barley (76.1) and oat (44.7) have been reported in Finland [28]. A median total phytosterol concentration of $49 \mathrm{mg} / 100 \mathrm{~g}$ (range 4.1-344) edible portion has been reported for some cereal foods commonly consumed in Sweden and in the Netherlands, $\beta$-sitosterol generally being the dominant form (62\%), followed by campesterol (21\%) and, in smaller concentrations, stigmasterol (4\%), $\beta$-sitostanol $(4 \%)$ and campestanol (2\%) [33]. Free and esterified sterol contents of 52.7 and $52.8 \mathrm{mg} / 100 \mathrm{~g}$, respectively, have been reported in spelt (Triticum spelta) and winter wheat (Triticum aestivum), which also contain 123.8 and $112.6 \mathrm{mg} / 100 \mathrm{~g}$, respectively, of glycosylated sterols [34].

Phytosterols have also been quantified in nuts and seeds commonly consumed in the United States - the highest and lowest phytosterol contents corresponding to sesame seed and wheat germ (400-413 mg/100 g), and the lowest to Brazil nuts $(95 \mathrm{mg} / 100 \mathrm{~g})$. Beta-sitosterol, $\Delta^{5}$-avenasterol and campesterol were found to be the predominant forms. It should be noted that the values obtained include steryl glycosides, which represent a significant proportion of total sterols in nuts and seeds [35].

In nuts (walnuts, almonds, peanuts, hazelnuts and the macadamia nuts), $\beta$-sitosterol is the most abundant sterol, the total sterol contents ranging from 99.12 to $207.17 \mathrm{mg} / 100 \mathrm{~g}$ oil. Only small differences were found between the campesterol and stigmasterol contents [36]. In walnuts, a campesterol content of $6 \mathrm{mg} / 100 \mathrm{~g}$, and trace levels of stigmasterol have been reported [24]. The levels of stigmasterol of 3.81 and $3.83 \mathrm{mg} / 100 \mathrm{~g}$ oil in hazel and macadamia nuts mentioned by Maguire et al. [36], are in line with the reports of different authors [37-40].

The free and esterified sterol concentrations in 31 edible oils and fats, including individual values for sitosterol, campesterol, stigmasterol, brassicasterol, $\Delta^{5}$-avenasterols, sitostanol, campestanol, and cholesterol, have been reported [41]. A high variability in the proportion of free and esterified sterols has been reported among different oils and fats. In soybean oil, stigmasterol and sitosterol contents of 61 and $118 \mathrm{mg} / 100 \mathrm{~g}$, respectively, have been recorded [42].

Among foods of animal origin, particularly bivalve shell fish species, 20 different sterols with cholesterol present as the major sterol (19-39\%) and trans-22-dehydrocholesterol, brassicasterol, 24-methylenecholesterol and campesterol individually accounting for $>10 \%$ in at least one species, have been detected. This wide range of sterols in bivalves reflects their varied phytoplankton food sources [43].

\section{Estimated average intakes of phytosterols}

The estimated daily dietary intakes of plant sterols among different populations range from 160 to $400 \mathrm{mg}$ [44]. 
The average intakes of phytosterols have been estimated between 140 and $360 \mathrm{mg} /$ day in Finland [45] and $163 \mathrm{mg} /$ day in the United Kingdom [46].

In the Netherlands, the mean intakes (mg/day) of cholesterol (202), campesterol (27), stigmasterol (15), and $\beta$-sitosterol (102) have been estimated by gas-chromatographic (GC) determination of non-derivatized sterols in duplicate 24-h diets (among 123 people, in the spring and autumn of 1994) [47]. On the other hand, the Netherlands Cohort Study on Diet and Cancer reported a mean intake of $359 \mathrm{mg}$ phytosterols/day, of which $64 \%$ corresponded to $\beta$-sitosterol, $18 \%$ to campesterol, and $9 \%$ to stigmasterol [48].

Plant sterols are less efficiently absorbed than cholesterol (2-5 and $60 \%$, respectively) [49,50], while phytostanols are more poorly absorbed than phytosterols.

\section{Analytical methods}

The physiological effects of phytosterols, and mainly their cholesterol-lowering properties, have increased interest in their occurrence in foods and diets. As a result, there is also growing interest in their determination in foods, where phytosterols and phytostanols can be intrinsic or added, and analytical methods for measuring them have been developed.

As mentioned above, plant sterols are found in foods as free sterols, steryl esters, steryl glycosides and acylated steryl glycosides [30]. In turn, in sterol-enriched foods, phytostanols, phytosterol and phytosterol/phytostanol esters have been used. Thus, the ideal sample preparation procedure for total sterol determination would include the analysis of all possible conjugates of sterols [32].

In most cases, the determination of sterol components is based on the analysis of sterols as alcohols instead of steryl/stanyl esters as such, which is good from the labeling point of view-requiring the free sterol contents to be stated.

It should be noted that no official reference methods has been especially developed for the analysis of phytostanols or phytosterols in sterol-enriched foodstuffs. Some international reference methods exist for the analysis of sterol fractions of fats and oils, such as the ISO 6799 [51], IUPAC methods 2.401 [52] and 2.403 [53], ISO 12228 [54] and AOCS Ch 6-91 [55]. Also, Codex Stan 210 [56] refers to ISO 6799 [51] and IUPAC 2.403 [53] methods. All these methods have been developed for the analysis of sterols as natural minor food components, meaning that the sterol contents are $1 \%$ or lower, whereas in functional food products the stanol/sterol concentrations presently may be as high as $8 \%$ [5].

An excellent and comprehensive review of the chromatographic methods used in sterol determination has been carried out by Abidi [57]. In the present review, different steps of the analysis will be discussed.

The determination of phytosterols in plant material is usually performed by capillary gas chromatography (GC), with flame ionization detection (FID) or mass spectrometry (MS) to confirm peak identity, although HPLC can also be used. However, it is GC of sterol silyl ether (or acetate derivatives) coupled with electron impact or chemical ionization MS that provides the most effective resolution, identification and quantitation (by selected ion monitoring) [58]. Validation methods for the determination of sterols in foods, diet samples and in human serum, including quality control checking analyses, using GC-FID have been published [32,33,59].

Typically, the analysis of individual sterols includes the extraction of lipids, saponification or acid hydrolysis and saponification to liberate sterols, extraction of unsaponifiable matter and separation/partial purification of sterols, e.g., by TLC or SPE, the formation of sterols derivatives, and their analysis by capillary GC $[5,32,47,60]$.

\subsection{Sample storage conditions}

Sterols are unstable components, which is why the storage conditions of the sample prior to determination must be taken into account. As an example, it has been shown that sterols are more stable in non-lyophilized material (homogenized diet) stored at $-20{ }^{\circ} \mathrm{C}$ than in lyophilized material stored at $4{ }^{\circ} \mathrm{C}$; in this case after 6 weeks of storage, the sterol content decreased and the chromatogram showed additional peaks [47].

\subsection{Sample preparation}

One of the most critical steps in the analysis of biological fluids and compounds in biological matrices is sample preparation. To prevent sterol oxidation, the oxygen has to be removed by blowing nitrogen, and anti-oxidants such as pyrogallol can also be used [47].

A reliable sample preparation method has been developed for the GC measurement of the total contents (including free, esterified and glycosylated forms) of individual sterols in foods [32].

\subsubsection{Solvent extraction}

The isolation technique to be applied depends on the nature of the matrix, its physical state (liquid or solid), and also on the form (free, esterified and glycosylated) in which sterols occur within the matrix.

Phytosterols in plant tissues and seed oils can be isolated by solvent extraction with chloroform-methanol [61], chloroform-methanol-water [62,63], hexane [64-66], methylene chloride [67,68] or acetone [69] followed by alkaline hydrolysis and chromatographic purification to obtain enriched total sterols.

The solvent system chloroform-methanol-water [62,63] has been applied by Thompson and Merola [70] to determine cholesterol in multicomponent foods as an alternative method to the $\mathrm{AOAC}$ [71], and has been reported to be capable of determining major non-glycosidic plant sterols. A modification of this method has been applied for the determination of plant sterol contents in research diets [59].

A solid phase extraction (SPE) method using neutral alumina cartridges has been applied for the extraction of free and esterified sterols from oils and fats [41].

Lipids from vegetables can also be extracted by supercritical fluid extraction (SFE) with supercritical $\mathrm{CO}_{2}$, after which sterols can be enriched and isolated following saponification [72,73] or supercritical fluid fractionation (SFF) [74] together 
with additional sample clean up using different chromatographic techniques.

To isolate the non-glyceridic components (hydrocarbons, tocopherols, sterols and sterol esters) from the slightly more polar triacylglycerol matrix, solid phase extraction SPE (silicagel) has been used [75]. Prior to SPE, the free hydroxyl group of sterols and tocopherols were silylated to reduce their polarity. The eluted fraction was then analyzed by GC. As compared to solvent extraction, SPE is an environmentally more friendly technique which provides a more convenient way for sample extraction, with a reduced loss of sterol analytes.

\subsubsection{Saponification}

Direct saponification methods have been applied for the determination of plant sterols in pasta products [76] and in multicomponent diet samples [47]. However, the acetal bond between the sterol and the carbohydrate moiety cannot be hydrolyzed in alkaline conditions, and therefore direct saponification methods fail to quantify steryl glycosides [77]. Some matrices such as cereals require acid hydrolysis to release bound sterols in cereals [4].

Acid hydrolysis $(6 \mathrm{M} \mathrm{HCl})$, alkaline saponification $(96 \%$ ethanolic $\mathrm{KOH}$ ) and lipid extraction with toluene have been used for the determination of phytosterols and phytostanols in cereal products [25]. A combination of acid hydrolysis and alkaline hydrolysis is superior to alkaline hydrolysis alone [32,78].

Saponifications are quite laborious for routine analysis, and on the other hand, acid hydrolysis is not applicable to $\Delta^{7}$-phytosterols (e.g., $\Delta^{7}$-avenasterol, $\Delta^{7}$-stigmastenol, etc.), because they decompose or isomerize after a short time of acidic hydrolysis [79]. The occurrence of $\Delta^{7}$-sterols appears to be restricted to only a few plant families, e.g. Cucurbitaceae and Theaceae. In refined vegetable oils, sterols occur only in free and esterified form, because steryl glycosides, if originally present, are removed during the oil refining process $[1,32]$.

Saponifications with ethanolic potassium hydroxide, either at room temperature or with heating (hot saponification) have been described: hot saponification with ethanolic potassium hydroxide in the presence of an internal standard ( $5 \beta$-cholestan$3 \alpha$-ol) is adequate for most matrices having added phytosterols/phytostanols, such as spread, milk and yoghurt [5]. In saponification at room temperature, an aliquot of lipid extract or oil sample is stirred overnight at room temperature with $1 \mathrm{M}$ ethanolic potassium hydroxide [64,80,81].

To obtain total free, esterified and glycosidic sterols, acid hydrolysis has to be applied to the lipid extract. Acid hydrolysis is carried out with $0.5 \mathrm{M}$ methanolic $\mathrm{HCl}$ in a Teflon screwcap test tube with a leak-proof cap at $75 \pm 2{ }^{\circ} \mathrm{C}$ for $22 \mathrm{~h}$, with constant shaking at $145 \mathrm{rpm}$ [82].

Although the isolation of unsaponifiable material containing, among others, phytostanols and phytosterols, after saponification by organic solvent extraction can be rather time consuming, most methods use multiple extractions in a separator funnel with an organic solvent (diethyl ether, ether, light petroleum or heptane)-followed by evaporation of solvent to dryness. However, during washing and shaking, difficult to break emulsions may be formed. The use of small columns of aluminum oxide (alumina) in a form of solid phase extraction can replace extractions, avoiding emulsions and saving a lot of time during serial analyses. In addition, reproducibility can be improved. The soap solution is applied as is, i.e., in ethanol, to a small aluminum oxide column. The potassium salts of free fatty acids are strongly bound to the aluminum oxide surface by the formation of highly insoluble aluminum soaps. The unsaponifiable component is then eluted from the column with ether [83].

Sterol extracts usually require further clean up and/or enrichment techniques to remove interferences.

\subsubsection{Purification/enrichment techniques}

Column chromatography (CC) and thin layer chromatography (TLC) are accessible and affordable separation techniques $[79,84]$, the choice depending on the amount of sample to be processed. Both techniques are adequate for sample clean up, purification, qualitative assays and preliminary sterol estimation studies [57].

TLC on silica gel with suitable mobile phases has been used to fractionate lipid or non-saponifiable lipid extracts $[85,86]$. Spots can be visualized with a UV lamp on a silicagel plate impregnated with a fluorescence indicator such as dichlorofluorescein.

However, the fractionation of sterols with CC and TLC is time consuming and therefore not suitable for routine analysis. That is why in the purification and/or fractionation of lipid extracts or non-saponifiable fractions, these techniques have often been replaced by solid phase extraction (SPE) cartridges, providing faster fractionation and using smaller volumes of solvent. Solid phase microextraction (SPME) is presently widely used separation/preparation methods for biological samples [29].

SPE has been used in reverse-phase (RP) mode (octadecylsilica) to isolate the sterol fraction from the unsaponifiable extract, and in normal-phase (NP) mode to separate trimethylsilyl (TMS) derivatives from a non-saponified vegetable oil sample [87]. Neutral alumina SPE cartridges have been used for the determination of both free and esterified sterols [41]. To separate free sterols from steryl glycosides, silica SPE cartridges have been employed [38,79].

\subsection{Determination}

\subsubsection{Gas chromatography}

Capillary gas chromatography (GC) has been the technique of choice for the analysis of sterols and related compounds. Capillary columns offer shorter analysis times and lesser peak interference, improvement in component resolution, and high thermal stability compared with packed columns [57].

The majority of sterol determinations have been carried out with non-polar stationary phases (100\% polysiloxane phases) in capillary columns. However, the use of a slightly polar stationary phase, for instance 5\% diphenyl-95\% dimethylpolysiloxane of high thermal stability, provides better resolution of the peaks - allowing almost baseline separation of the trimethylsilyl (TMS) ether derivatives from the campesterol/campestanol and sitosterol/sitostanol pairs. Similar separation is not achieved with non-polar stationary phases 
coated with $100 \%$ methyl polysiloxane. An excellent separation of campesterol and campestanol, and of sitosterol, sitostanol and $\Delta^{5}$-avenasterol has been achieved with a fused-silica capillary column (14\% cyanopropyl-phenyl-methylpolysiloxane) of low/medium polarity [88].

Although the separation of sterols and stanols as such without derivatization is possible [46], the resolution of a sterol and its corresponding stanol is not as good as that of their trimethylsilyl (TMS) derivatives. Thus, usually prior to capillary GC, sterols and stanols are conventionally transformed into derivatives that yield improved peak shape, resolution and sensitivity, and a higher stability for the thermally labile unsaturated sterols [5]. Sterols are commonly analyzed as their trimethylsilyl (TMS) or acetate derivatives. The former are more suitable for the GC-MS characterization and quantitation of sterols.

Derivatizing agents usually utilized: $N$-methyl- $N$-trimethylsilyltrifluoroacetamide (MSTFA) in anhydrous pyridine and bis(trimethylsilyl)-trifluoroacetamide (BSTFA) containing 1\% of trimethylchlorosilane (TMCS) $(1: 1, \mathrm{v} / \mathrm{v})$ added to a dried sample.

Simultaneous derivatization with BSTFA and extraction (by SPME) can also be carried out. Prior to extraction, the fiber (polyacrylate) is coated with BSTFA in the vapor phase, and on sampling the analytes (saponified sample) are converted into derivatives that have a high affinity for the coating. The procedure was applied to the determination of three precursors in the cholesterol biosynthesis pathway (desmosterol, lathosterol and lanosterol) and the determination of two phytosterols (sitosterol and sitostanol) in serum. The internal standard (IS) was $5 \alpha$ cholestane. The serum matrix interferes with the SPME method, and the standard addition procedure must be applied for quantitation [29].

Selection of internal standard (IS): to eliminate analytical errors due to fluctuations in instrument operation conditions and other experimental variables, GC peaks of sterols are represented by their retention times relative to a reference standard or an internal standard (IS). On the other hand, losses of sterol analytes during isolation and separation must be corrected for the final results of analyte quantification by using radioisotopes or most frequently internal standardization with standards not present in samples [89].

The IS most commonly used in sterol determinations have been betulin, cholestane, $5 \beta$-cholestan-3 $\alpha$-ol (epicoprostanol) and $5 \alpha$-cholestan-3 $\beta$-ol $[5,31,85,90,91]$. However, an IS should be similar to the analytes, and cholestane is a sterol hydrocarbon lacking the position 3 hydroxyl group which is typical of sterols, while betulin has two hydroxyl groups and its structure and chemical properties differ even more from those of sterols. Thus, cholestane and betulin are not the best choices. In addition, their FID detector responses differ from those of sterols. Thus, the use of cholestane or betulin as IS would require detector response factors to be determined for sterols [5]. For most matrices $5 \beta$-cholestan- $3 \alpha$-ol (epicoprostanol) has been found to be adequate. Its structure closely resembles those of sterols, and it is absent from plant sterol samples. Its FID detector response is similar to that of stanols/sterols. Thus, correction factors are not needed for quantitation [5]. A chromatogram of phytosterols commonly found in foods using cholestane as IS is shown in Fig. 2.

However, $5 \alpha$-cholestan-3 $\beta$-ol ( $\beta$-cholestanol) cannot be used for stanol analysis because samples may contain small amounts of cholestanol (dihydrocholesterol), which is the hydrogenation product of cholesterol.

Cholestanol and sitostanol are not suitable as IS, because they may occur in many fats. For this reason, some sterol determination methods such as for example the European olive oil method $[83,92]$, recommend two analyses-one with cholestanol or sitostanol added as IS, plus one without the IS. In many cases, the use of a standard such as betulin, which is known not to occur in fats, can drastically cut the required number of analyses.

GC methods described for the determination of sterols in foods and published posterior to the comprehensive review carried out by Abidi [57], are included in Table 1. Sterols are routinely analyzed by GC-FID based on retention times, while GC-MS is used to confirm peak identities.

\subsubsection{Liquid chromatography}

Compared with GC, HPLC offers the advantage of operating under milder column temperatures, and under non-destructive detection conditions. It therefore seems suitable for the analysis of thermally unstable compounds such as sterols. However, the high lipophilicity of sterols can make sample processing and chromatography difficult. Potential contamination in the column or autoinjector has been minimized by using a high organic solvent content.

Normal-phase (NP) and reversed-phase (RP) HPLC techniques have been widely used for the analysis of lipid classes and individual sterols in various sample matrices. RP-HPLC uses less volatile polar organic solvents in water, and offers ready equilibration in a bonded silica stationary phase with the mobile phase solvents, compared with NP-HPLC; in general, RP-HPLC has been more frequently and more widely used than NP-HPLC for the separation of individual sterols [57].

The most frequently used options have been alkylsilica stationary phases, and among them octadecylsilica (ODS) columns. As mobile phases, organic solvents (acetonitrile, methanol) or their aqueous solutions (depending on the analyte structures and sample matrices involved) have been used.

HPLC methods described for the determination of sterols in foods and published posterior to the comprehensive review carried out by Abidi [57], are included in Table 2. Sterol detection has been carried out by UV (200-210 nm), photodiode array detection (DAD), refractive index (RI) detection, evaporative light scattering detection (ELSD), nuclear magnetic resonance (NMR) detection and mass spectrometry (MS), see Table 2.

RP-HPLC in combination with UV or light scattering detection has been shown to be useful for the analysis of molecular species of steryl glycosides and acylated steryl glycosides $[93,94]$. Prior to LC separation, TLC was applied for sample clean up and for the separation of different steryl species. The acylated species (steryl esters and acylated steryl glycosides) were converted to the corresponding non-acetylated species (free sterols and steryl glycosides) by alkaline hydrolysis. Using 


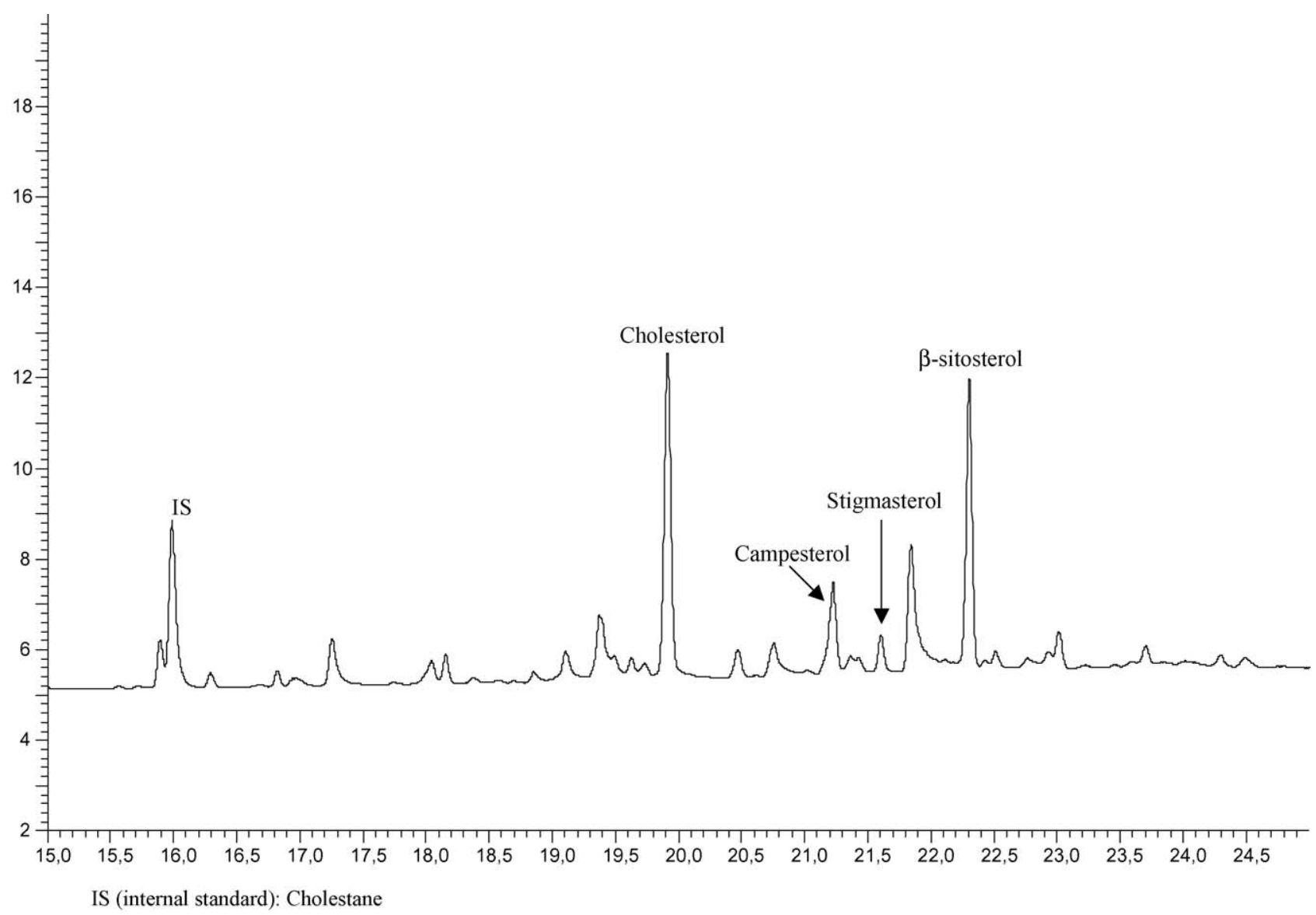

Fig. 2. GC-FID of TMS-phytosterols from a milk-cereal based infant food. Column Equity-5-poly $(5 \%$ diphenyl/95\% dimethylsiloxane) $30 \mathrm{~mm} \times 0.25 \mathrm{~mm}$, $d=0.25 \mu \mathrm{m}$.

HPLC in combination with UV detection $(200 \mathrm{~nm})$, free sterol standards can be used to quantify steryl glycosides, since at low wavelengths the glycosidic residues do not affect the UV absorption properties of steryl glycosides [94].

In HPLC-MS analysis, baseline separation of peaks is not always necessary, due to the high specificity and selectivity of the detection method. Recently, atmospheric pressure chemical ionization (APCI) with liquid chromatography mass spectrometry (LC-MS) was found to be suitable for sterol analyses in different samples matrices. LC-APCI-MS has been used to identify sterols in soybean oil [42], to characterize phytosterols in spelt [95], to determine ergosterol levels in bulrush [96] and to measure cholesterol oxides in different food supplies [97]. Because sterols are highly lipophilic with few polar functional groups, they are difficult to ionize through conventional electrospray methods [95]. APCI ionization is usable but is not the most sensitive method. Electron impact (EI) ionization in particular, and the recently developed atmospheric pressure photoionization (APPI) technique, are effective alternatives for lipophilic compounds [98]. However, APCI ionization is most widely used for the sterols analysis. APCI instruments are moreover commonly available, and APCI ionization can be easily coupled to the HPLC system.

MS yields the most effective resolution, identification and quantitation (via selected ion monitoring) [58]. Intense fragment ions $(\mathrm{m} / \mathrm{z}$ 369, 395, 397 and 399 for cholesterol, stigmasterol, sitosterol and sitostanol, respectively) have been observed, indicating the loss of water $\left[M+\mathrm{H}-\mathrm{H}_{2} \mathrm{O}\right]^{+}$. This seems to be characteristic of sterols, as dehydration was observed in earlier reports with cholesterol oxides [97], phytosterols [42,95] and ergosterol [96].

MS/MS detection is known to be specific and selective. However, in MS/MS spectra of sterols, the product ion spectra of the $\left[M+\mathrm{H}-\mathrm{H}_{2} \mathrm{O}\right]^{+}$ions were quite similar to those obtained with MS.

The response factors expressed by the ratio of free sterols over ergosterol peak areas at $100 \mu \mathrm{g} / \mathrm{ml}$ in the determination of several sterols in cereal by LC/MS ${ }^{2}$ have been calculated [34]. It was found that response factors were related to sterol structure. Indeed, saturated sterols, with no double bond in the ring structure, exhibited low response factors $(0.25-0.31)$, whereas unsaturated sterols with one double bond in the ring structure had high response factors (0.89-1.42). Further differences observed within free sterol response factors could be explained by differences in the sterol side chains [94].

On-line liquid chromatography-gas chromatography (LC-GC) has been applied to the detection of vegetable oils in milk fat using $\beta$-sitosterol as marker. The method involves trans-esterification of the fat, pre-separation of the sterol fraction from other lipid constituents, and on-line transfer to 
Table 1

GC analysis of phytosterols in foods

\begin{tabular}{|c|c|c|c|c|c|}
\hline Method detection & Stationary phase (supplier) & Internal standard & Sterol investigated (derivative) & Food & Reference \\
\hline FID & $\begin{array}{l}\mathrm{HP} 5, d_{\mathrm{f}}=0.25 \mu \mathrm{m}, 30 \mathrm{~m} \times 0.32 \mathrm{~mm} \\
\text { (Hewlett-Packard) }\end{array}$ & Betulin & $\begin{array}{l}\text { Brassicasterol, campesterol, stigmasterol, } \beta \text {-sitosterol, } \\
\Delta^{5} \text {-avenasterol (Sylon BFT:pyridine, 1:1) }\end{array}$ & Milk, margarine & [102] \\
\hline FID & $\begin{array}{l}\mathrm{DB}-5, d_{\mathrm{f}}=0.25 \mu \mathrm{m}, 30 \mathrm{~m} \times 0.25 \mathrm{~mm} \\
(\mathrm{~J} \& \mathrm{~W})\end{array}$ & $\begin{array}{l}\text { Cholesteryl } \\
\text { heptadecanoate }\end{array}$ & $\begin{array}{l}\text { Brassicasterol, campesterol, stigmasterol, } \beta \text {-sitosterol, } \\
\Delta^{7} \text {-stigmasterol }\end{array}$ & Vegetable oils & [103] \\
\hline FID & $\begin{array}{l}\text { Rtx- } 5, d_{\mathrm{f}}=0.1 \mu \mathrm{m}, 60 \mathrm{~m} \times 0.25 \mathrm{~mm} \\
\text { (Restek) }\end{array}$ & $\begin{array}{l}\text { Dihydrocholesterol } \\
\text { (=cholestanol) }\end{array}$ & $\begin{array}{l}\text { Cholesterol, brassicasterol, campesterol, stigmasterol, } \\
\text { sitosterol, } \Delta^{5} \text {-avenasterol, others (stanols: campestanol, } \\
\text { sitostanol) (BSTFA with } 1 \% \text { of TMCS in pyridine) (TMS) }\end{array}$ & Whole-wheat flour and diet composite & {$[32]$} \\
\hline FID-MS & Rtx-5 (Restek) & & Brassicasterol, campesterol, sitosterol, others (stanols) (TMS) & $\begin{array}{l}\text { Oils, margarines, cereal products, } \\
\text { vegetables, fruits, berries }\end{array}$ & {$[26]$} \\
\hline FID-MS & $\begin{array}{l}\text { CP Sil- } 8, d_{\mathrm{f}}=0.25 \mu \mathrm{m}, \\
30 \mathrm{~m} \times 0.32 \mathrm{~mm} \text { (Varian) or HP- } 5 \text {, } \\
d_{\mathrm{f}}=0.25 \mu \mathrm{m}, 30 \mathrm{~m} \times 0.25 \mathrm{~mm}\end{array}$ & & $\begin{array}{l}\text { Cholesterol, 24-nordehydrocholesterol, } \\
\text { trans-22-dehydrocholesterol, brassicasterol, } \\
\text { 24-methylenecholesterol, campesterol, sitosterol }\end{array}$ & Seafood: bivalves & [43] \\
\hline FID-MS & $\begin{array}{l}\text { HP-35, } d_{\mathrm{f}}=0.25 \mu \mathrm{m} \\
30 \mathrm{~m} \times 0.25 \mathrm{~mm} \text { (Hewlett-Packard) }\end{array}$ & Dihydrocholesterol & $\begin{array}{l}\text { Brassicasterol, campesterol, stigmasterol, } \beta \text {-sitosterol, } \\
\Delta^{5} \text {-avenasterol (BSTFA:pyridine, } 2: 1 \text { in TBME) }\end{array}$ & Plant matrices & [79] \\
\hline FID-MS & $\begin{array}{l}\text { Rtx-1701, } d_{\mathrm{f}}=0.25 \mu \mathrm{m} \\
60 \mathrm{~m} \times 0.25 \mathrm{~mm}, \text { HP-5, } \\
30 \mathrm{~m} \times 0.32 \mathrm{~mm} \text { (Restek) }\end{array}$ & Epicholesterol & $\begin{array}{l}\text { Sitosterol, campesterol, stigmasterol, brassicasterol, } \\
\Delta^{5} \text {-avenasterol, cholesterol, others (sitostanol, campestanol), } \\
\text { (BSTFA with } 1 \% \text { of TMCS) (TMS) }\end{array}$ & Edible oils and fats & [41] \\
\hline FID-MS & Rtx-5 (Restek) & & $\begin{array}{l}\beta \text {-Sitosterol, campesterol, stigmasterols, } \Delta^{5} \text {-avenasterol, } \\
\text { sitostanol, campestanol }\end{array}$ & Nuts and seeds & {$[27]$} \\
\hline FID & $\begin{array}{l}\text { Rtx- } 5, d_{\mathrm{f}}=0.25 \mu \mathrm{m}, 15 \mathrm{~m} \times 0.32 \mathrm{~mm} \\
\text { (Restek) }\end{array}$ & Epicholesterol & $\begin{array}{l}\beta \text {-Sitosterol and other ( } \beta \text {-sitosterol glucoside) (BSTFA:TMCS, } \\
1: 1) \text { (TMS) }\end{array}$ & $\begin{array}{l}\text { Dietary supplements, whole wheat flour, } \\
\text { peanut butter, flaxseed, granola bars, } \\
\text { soybeans, dried figs, lyophilized mixed } \\
\text { vegetables, almonds, pine nuts, diet } \\
\text { homogenate }\end{array}$ & {$[35]$} \\
\hline
\end{tabular}


Table 2

HPLC analysis of phytosterols in foods

\begin{tabular}{|c|c|c|c|c|c|}
\hline Method detection & Stationary phase [mobile phase] (supplier) & Internal standard & Sterol investigated (derivative) & Food & References \\
\hline UV $208 \mathrm{~nm}$, APCI-MS & $\begin{array}{l}\mathrm{C}_{8} \text { narrow-bore } 5 \mu \mathrm{m}, 150 \mathrm{~mm} \times 2.1 \mathrm{~mm} \\
{[\mathrm{MeCN} \text {-water }(86: 14)](\text { Supelco })}\end{array}$ & 6-Ketocholestanol & Sitosterol and stigmasterol & Vegetable oils & [42] \\
\hline DAD & $\begin{array}{l}\text { Luna C8 } 250 \mathrm{~mm} \times 4.6 \mathrm{~mm}[\mathrm{MeCN} \text {-water } \\
(80: 20)](\text { Phenomenex })\end{array}$ & & Campesterol, stigmasterol, $\beta$-sitosterol & $\begin{array}{l}\text { Edible nuts: walnuts, almonds, } \\
\text { peanuts, hazelnuts, macadamia nut }\end{array}$ & [36] \\
\hline DAD & $\begin{array}{l}\text { Luna C8 } 3 \mu \mathrm{m}, 150 \mathrm{~mm} \times 2 \mathrm{~mm}[\mathrm{MeCN} \text {-water } \\
(80: 20)] \text { (Phenomenex) }\end{array}$ & & $\beta$-Sitosterol & Vegetable oils & [104] \\
\hline ELSD-MS & $\begin{array}{l}\text { Hypersil BDS RP18 } 5 \mu \mathrm{m}, 250 \mathrm{~mm} \times 4 \mathrm{~mm} \\
{[\text { MeOH-MeCN-water }(75: 15: 10)]} \\
\text { (Hewlett-Packard) }\end{array}$ & $\begin{array}{l}\text { Cholesterol- } \beta \text {-D- } \\
\text { glucoside }\end{array}$ & $\begin{array}{l}\text { Steryl glycosides and acylated steryl glycosides: } \\
\text { brassicasterol, campesterol + stigmasterol, } \\
\beta \text {-sitosterol, } \Delta^{5} \text {-avenasterol }\end{array}$ & Plant matrices & [79] \\
\hline APCI-MS & $\begin{array}{l}\text { Luna Hexyl-Phenyl } 3 \mu \mathrm{m}, 100 \mathrm{~mm} \times 2 \mathrm{~mm} \\
{[\mathrm{~A}=\mathrm{MeCN}, \mathrm{B}=\text { water, gradient elution }]} \\
(\text { Phenomenex })\end{array}$ & Cholesteryl decanoate & $\begin{array}{l}\text { Campesterol, stigmasterol, } \beta \text {-sitosterol, sitostanol, } \\
\text { campestanol }\end{array}$ & Juices and margarine spreads & [105] \\
\hline APCI-MS & $\begin{array}{l}\mathrm{C}_{18} \text { Prevail } 2 \mu \mathrm{m}, 150 \mathrm{~mm} \times 2.1 \mathrm{~mm} \\
\text { [A = MeOH, } \mathrm{B}=\text { water }(1 \% \mathrm{MeCN}) \text {, gradient } \\
\text { elution] }\end{array}$ & & $\begin{array}{l}\text { Glycosylated and free sterols: ergosterol, } \\
\Delta^{5} \text {-avenasterol, } \Delta^{7} \text {-avenasterol, stigmasterol, } \\
\text { campesterol, } \beta \text {-sitosterol; campestanol, } \beta \text {-sitostanol }\end{array}$ & Cereals (spelt and wheat) & {$[95,34]$} \\
\hline DAD & $\begin{array}{l}\text { Luna } \mathrm{C}_{18} 5 \mu \mathrm{m}, 250 \mathrm{~mm} \times 2 \mathrm{~mm}[\mathrm{MeOH}] \\
\text { (Phenomenex) }\end{array}$ & & $\begin{array}{l}\gamma \text {-Oryzanol: campesterylferulate, } \\
\text { campestanylferulate, } \beta \text {-sitosterylferulate, } \\
\text { cycloartenylferulate, cycloartenylferulate, } \\
\text { 24-methylencycloartanylferulate }\end{array}$ & Crude rice bran oil & [106] \\
\hline APCI-MS & $\begin{array}{l}\text { Prontosil 200-3-C30 } 3 \mu \mathrm{m}, 250 \mathrm{~mm} \times 2 \mathrm{~mm} \\
{[\mathrm{MeOH}-t \text {-BME (80:20)] (Bischoff) }}\end{array}$ & & & & \\
\hline On-line LC UV-GC-FID & $\begin{array}{l}\text { Hypersil } 2.1 \mathrm{~mm} \times 100 \mathrm{~mm}, 60 \AA, 5 \mu \mathrm{m} \text {, Agilent } \\
{[0.8 \% 2 \text {-propanol in } n \text {-hexane] }(\mathrm{GC}: \mathrm{CP} \text {-Sil8CB }} \\
d_{\mathrm{f}}=0.4 \mu \mathrm{m}, 25 \mathrm{~m} \times 0.25 \mathrm{~mm}, \text { Chromopack) }\end{array}$ & Stigmasterol & $\begin{array}{l}\beta \text {-Sitosterol (as marker of milk fat adulteration with } \\
\text { vegetable oils) }\end{array}$ & Milk fat & [99] \\
\hline APCI-MS & $\begin{array}{l}\text { X-Terra MS C8 } 3.5 \mu \mathrm{m}, 150 \mathrm{~mm} \times 2.1 \mathrm{~mm} \\
{[\mathrm{MeOH} \text {-water (90:10)] (Waters) }}\end{array}$ & Stigmasterol & Sitosterol, sitostanol & Caco- 2 cells (availability assay) & [107] \\
\hline
\end{tabular}


the capillary GC system. This method avoids time-consuming sample preparation steps prior to GC analysis [99].

Supercritical fluid chromatography (SFC) employs inert supercritical carbon dioxide as mobile phase eluent. The technique is suitable for the analysis of phytosterols in vegetable oils [100]. Coupling supercritical fluid extraction (SFE) with SFC enables sample extraction, pre-concentration, preparative fractionation and chromatographic quantitation in a single operation $[72,101]$.

\section{Conclusions}

According to their sensitivity and precision, the currently available techniques for sterol analysis can be classified as follows: GC $>$ HPLC $>$ SFC. The sensitivity order may vary depending on the sterol structures and detectors coupled to the chromatographic instruments. As reported above, GC-FID (or MS, when peak identity confirmation is needed) can be considered the method of choice for the determination of phytosterols in foods and diets.

It should also be noted that each matrix is unique, and conditions have to be selected to optimize the accuracy/yield of all forms of sterols in different sample types. On the other hand, faster procedures must be developed to facilitate the control of functional foods with added phytosterols.

\section{Acknowledgment}

This review is part of the project BIO4-72 financially supported by the University of Valencia (Spain).

\section{References}

[1] S.P. Kochhar, Prog. Lipid Res. 22 (1983) 161-188.

[2] R.A. Moreau, B.D. Whitaker, K.B. Hicks, Prog. Lipid Res. 41 (2002) 457-500.

[3] D. Kritchevsky, S.C. Chen, Nutr. Res. 25 (2005) 413-428.

[4] P.C. Dutta, L.A. Appelqvist, J. Sci. Food Agric. 71 (1996) 383-391.

[5] P. Laakso, Eur. J. Lipid Sci. Technol. 107 (2005) 402-410.

[6] K.B. Hicks, R.A. Moreau, Food Technol. 55 (2001) 63-67.

[7] EU-Scientific Committee on Food: European commission, Opinion of SCF on a request for the safety assessment of the use of phytosterol esters in yellow fat spreads, 2000. Available: http://europa.eu.int/comm/food/fs/sc/scf/out56_en.pdf.

[8] EU-Commission Regulation (EC) No. 608/2004 of 31 March 2004 concerning the labelling of foods and food ingredients with added phytosterols, phytosterol ester, phytostanols and/or phytostanol esters, OJ L97 of 1.04.2004, pp. 0044-0045.

[9] D.W. Peterson, Proc. Soc. Exp. Biol. Med. 78 (1951) 143-147.

[10] D.W. Peterson, C.W. Nichols Jr., E.A. Shneour, J. Nutr. 47 (1952) 57-65.

[11] D.W. Peterson, E.A. Schneour, N.F. Peck, H.W. Gaffey, J. Nutr. 50 (1953) 191-201.

[12] O.J. Pollak, Circulation 7 (1953) 702-706.

[13] H.F.J. Hendriks, J.A. Weststrate, T. van Vliet, G.W. Meijer, Eur. J. Clin. Nutr. 53 (1999) 319-327.

[14] A. Sierksma, J.A. Weststrate, G.W. Meijer, Br. J. Nutr. 82 (1999) 273-282.

[15] FDA, Food labelling: Health claims: Plant sterol/stanol esters and coronary heart disease. Food Drug Admin. Fed. Reg. 65, 54686-54739. www.access.gpo.gov/su_docs/fedreg/a000908c.html.
[16] A. De Jong, J. Plat, R.P. Mensink, J. Nutr. Biochem. 14 (2003) 362-369.

[17] A.V. Rao, S.A. Janezic, Nutr. Cancer 18 (1992) 43-52.

[18] A.V. Rao, R. Koratkar, in: F. Shahidi (Ed.), Antinutrients and Phytochemicals in Food, ACS Symposium Series, American Chemical Society, Washington, DC, 1997, pp. 313-324.

[19] A.B. Awad, R.L. von Holtz, J.P. Cone, C.S. Fink, Y.C. Chen, Anticancer Res. 18 (1998) 471-473.

[20] A.B. Awad, R. Roy, C.S. Fink, Oncol. Rep. 10 (2003) 497-500.

[21] M.H. Moghadasian, B.M. McManus, D.V. Godin, B. Rodrigues, J.J. Frohlich, Circulation 99 (1999) 1733-1739.

[22] P.J. Bouic, Curr. Opin. Clin. Nutr. Metab. Care 4 (2001) 471-475.

[23] S.J. van Rensburg, W.M. Daniels, J.M. van Zyl, J.J. Taljaard, Metab. Brain Dis. 15 (2000) 257-265.

[24] J.L. Weihrauch, J.M. Gardner, J. Am. Diet. Assoc. 73 (1978) 39-47.

[25] L. Normén, M. Johansson, H. Andersson, Y. van Gameren, P. Dutta, Eur. J. Nutr. 38 (1999) 84-89.

[26] V. Piironen, J. Toivo, A.M. Lampi, J. Food Comp. Anal. 13 (2000) 619-624.

[27] K.M. Phillips, D.M. Ruggio, M. Ashraf-Khorassani, J. Agric. Food Chem. 53 (2005) 9436-9445.

[28] V. Piironen, J. Toivo, A.M. Lampi, Cereal Chem. 79 (2002) 148-154.

[29] C. Domeño, B. Ruiz, C. Nerín, Anal. Bioanal. Chem. 381 (2005) 1576-1583.

[30] T. Akihisa, W. Kokke, T. Tamura, in: G.W. Patterson, W.D. Ness (Eds.), Physiology and Biochemistry of Sterols, American Oil Chemists' Society, Champaign, IL, 1991, pp. 172-228.

[31] M. Fenton, J. Chromatogr. 624 (1992) 369-388.

[32] J. Toivo, K. Phillips, A.M. Lampi, V. Piironen, J. Food Comp. Anal. 14 (2001) 631-643.

[33] L. Normén, S. Bryngelsson, M. Johnsson, P. Evheden, L. Ellegard, H. Brants, H. Andersson, P. Dutta, J. Food Comp. Anal. 15 (2002) 693-704.

[34] N.L. Ruibal-Mendieta, R. Rozenberg, D.L. Delacroix, G. Petitjean, A. Dekeyser, C. Baccelli, C. Marques, N.M. Delzenne, M. Meurens, J.L. Habib-Jiwan, J. Quetin-Leclercq, J. Agric. Food Chem. 52 (2004) 4802-4807.

[35] K.M. Phillips, D.M. Ruggio, M. Ashraf-Khorassani, J. Food Lipids 12 (2005) 124-140.

[36] L.S. Maguire, S.M. O’Sullivan, K. Galvin, T.P. O'Connor, N.M. O’Brien, Int. J. Food Sci. Nutr. 55 (2004) 171-178.

[37] G.P. Savage, D.L. McNeill, P.C. Dutta, JAOCS 74 (1997) 755-759.

[38] J. Parcerisa, D.G. Richardson, M. Rafecas, R. Codony, J. Boatella, J. Chromatogr. A 805 (1998) 259-268.

[39] J. Parcerisa, I. Casals, J. Boatella, R. Codony, M. Rafecas, J. Chromatogr. A 881 (2000) 149-158.

[40] A. Kaijser, P. Dutta, G. Savage, Food Chem. 71 (2000) 67-70.

[41] K.M. Phillips, D.M. Ruggio, J.I. Toivo, M.A. Swank, A.H. Simpkins, J. Food Comp. Anal. 15 (2002) 123-142.

[42] M. Careri, L. Elviri, A. Mangia, J. Chromatogr. A 935 (2001) 249-257.

[43] L.A. Copeman, C.C. Parrish, J. Agric. Food Chem. 52 (2004) 4872-4881.

[44] A. Berger, P.J.H. Jones, S.S. Abumweis, Lipids Health Dis. 3 (2004), http://www.lipidworld.com/content/3/1/5.

[45] V. Piironen, A.M. Lampi, in: P.C. Dutta (Ed.), Phytosterols as Functional Food Components and Nutraceuticals, Marcel Dekker, Inc., New York, 2004, pp. 1-32.

[46] G.M. Morton, S.M. Lee, D.H. Buss, P. Lawrence, J. Hum. Nutr. Diet. 8 (1995) 429-440.

[47] A.A. Jekel, H.A.M.G. Vaessen, R.C. Schothorst, Fresen. J. Anal. Chem. 360 (1998) 595-600.

[48] A.L. Normén, H.A.M. Brants, L.E. Voorrips, H.A. Andersson, P.A. van den Brandt, R.A. Goldbohm, Am. J. Clin. Nutr. 74 (2001) 141-148.

[49] M.S. Bosner, L.G. Lange, W.F. Stenson, R.E. Ostlund Jr., J. Lipid Res. 40 (1999) 302-308.

[50] R.E. Ostlund Jr., J.B. McGill, C.-M. Zeng, D.F. Covey, J. Stearns, W.F. Stenson, C.A. Spilburg, Am. J. Physiol. Endocrinol. Metab. 282 (2002) E911-E916. 
[51] ISO 6799, International Organisation for Standardization, Geneve, Switzerland, 1991.

[52] International Union of Pure Applied Chemistry: Method 2.401, in: C. Paquot, A. Hautfenne (Eds.), Standard Methods for the Analysis of Oils, Fats and Derivatives, 7th ed., Blackwell Scientific Publication, Oxford, UK, 1987.

[53] International Union of Pure Applied Chemistry: Method 2.403, in: C. Paquot, A. Hautfenne (Eds.), Standard Methods for the Analysis of Oils, Fats and Derivatives, 7th ed., Blackwell Scientific Publication, Oxford, UK, 1987.

[54] ISO 12228: International Organisation for Standardization, Geneve, Switzerland, 1999.

[55] AOCS Official Method Ch 6-91, American Oil Chemists' Society, USA, 1997.

[56] Codex Standard for Named Vegetable Oils Codex-Stan 210, Codex Alimentarius, 1999.

[57] S.L. Abidi, J. Chromatogr. A 935 (2001) 173-201.

[58] P. Volin, J. Chromatogr. A 935 (2001) 125-140.

[59] K.M. Phillips, D.M. Ruggio, J.A. Bailey, J. Chromatogr. B 732 (1999) 17-29.

[60] V. Piironen, D.G. Lindsay, T.A. Miettinen, J. Toivo, A.M. Lampi, J. Sci. Food Agric. 80 (2000) 939-966.

[61] R.P. Evershed, V.L. Male, L.J. Goad, J. Chromatogr. 400 (1987) 187-205.

[62] J. Folch, M. Lees, G.H. Sloane-Stanley, J. Biol. Chem. 226 (1957) 497-509.

[63] E.G. Bligh, W.J. Dyer, Can. J. Biochem. Physiol. 37 (1959) 911-917.

[64] S.L. Abidi, G.R. List, K.A. Rennick, J. Am. Oil Chem. Soc. 76 (1999) 463-467.

[65] H.M.A. Mohamed, I.I. Awatif, Food Chem. 62 (1998) 269-276.

[66] R.A. Moreau, M.J. Powell, K.B. Hicks, J. Agric. Food Chem. 44 (1996) 2149-2154.

[67] T. Akihisa, Y. Kinura, K. Roy, P. Ghosh, S. Thakur, T. Tamura, Phytochemistry 35 (1994) 1309-1313.

[68] T. Akihisa, Y. Nishimura, N. Nakamura, K. Roy, P. Ghosh, S. Thakur, T. Tamura, Phytochemistry 31 (1992) 1765-1768.

[69] F.W. Claasen, C. van de Haar, T.A. van Beek, J. Dorado, M.J. MartinezInigo, R. Sierra-Alvarez, Phytochem. Anal. 11 (2000) 251-256.

[70] R.H. Thompson, G.V. Merola, J. AOAC Int. 76 (1993) 1057-1068.

[71] AOAC, Official Methods of Analysis, 14th ed., Association of Official Analytical Chemists, Arlington, VA, 1984.

[72] J.M. Snyder, J.W. King, S.L. Taylor, A.L. Neese, J. Am. Oil Chem. Soc. 76 (1999) 717-721.

[73] J.W. King, E. Sahle-Demessi, F. Temmelli, J.A. Teel, J. Supercrit. Fluids 10 (1997) 127-137.

[74] S.L. Taylor, J.W. King, J. Chromatogr. Sci. 38 (2000) 91-94.

[75] M. Lechner, B. Reiter, E. Lorbeer, J. Chromatogr. A 857 (1999) 231-238.

[76] M.I.P. Kovacs, J. Cereal Sci. 11 (1990) 291-297.

[77] R.C. Heupel, in: W.D. Nes, E.J. Parish (Eds.), Analysis of Sterols and others Biologically Significant Steroids, Academic Press, Inc., San Diego, CA, 1989, pp. 49-60.

[78] J. Toivo, A.M. Lampi, S. Aalto, V. Piironen, Food Chem. 68 (2000) 239-245.

[79] P. Breinhölder, L. Mosca, W. Lindner, J. Chromatogr. B 777 (2002) $67-82$.
[80] D. Firestone, Official Methods and Recommended Practices of the American Oil Chemists' Society, 4th ed., AOCS, Champaign, IL, 1990, Method Ce 3-75.

[81] N. Ibrahim, R.K. Puri, S. Kapila, N. Unklesbay, J. Food Sci. 55 (1990) 271-272.

[82] S. Nagy, H.E. Nordby, Lipids 6 (1971) 826-830.

[83] K. Aitzetmüller, L. Brühl, H.-J. Fiebig, Lipid 100 (1998) 429-435.

[84] C. Paquot, A. Hautfenne, Standard Methods for the Analysis of Oils, Fats and Derivatives, International Union of Pure and Applied Chemistry, 7th ed., Blackwell Scientific Publications, Oxford, UK, 1987, Section 2.403 .

[85] S. Ghosat, Phytochemistry 24 (1985) 1807-1810.

[86] W.D. Nes, R.C. Heupel, P.H. Le, J. Chem. Soc., Chem. Commun. 20 (1985) 1431-1433.

[87] J. Toivo, V. Piironen, P. Kalo, P. Varo, Chromatographia 48 (1998) 745-750.

[88] P.C. Dutta, L. Normen, J. Chromatogr. A 816 (1998) 177-184.

[89] B.A. Knights, Lipids 17 (1982) 204-208.

[90] A.M. Lampi, V. Piironen, J. Toivo, in: P.C. Dutta (Ed.), Phytosterols as Functional Food Components and Nutraceuticals, Marcel Dekker, Inc., New York, 2004, pp. 33-73.

[91] G.S.M.J.E. Duchateau, H.-G.M. Jansen, A.J.H. Louter, in: P.C. Dutta (Ed.), Phytosterols as Functional Food Components and Nutraceuticals, Marcel Dekker, Inc., New York, 2004, pp. 75-131.

[92] Commission Regulation (EEC) No. 2568/91, Annexe V, Determination of sterol composition and content gas chromatography with a capillary column, Off. J. Eur. Commun. L248 (1991) 15-22.

[93] L.J. Goad, T. Akihisa, Analysis of Sterols, Blackie, London, UK, 1997.

[94] J. Kelsemeier, W. Eichenberger, B. Urban, Plant Cell Physiol. 26 (1985) 463-471.

[95] R. Rozenberg, N.L. Ruibal-Mendieta, G. Petitjean, P. Cani, D.L. Delacroix, N.M. Delzenne, M. Meurens, J. Quetin-Leclercq, J.-L. Habib-Jiwan, J. Cereal Sci. 38 (2003) 189-197.

[96] J. Headley, K. Peru, B. Verna, R. Roberts, J. Chromatogr. A 958 (2002) 149-156.

[97] E. Razzazi-Fazeli, S. Kleineisen, W. Luf, J. Chromatogr. A 896 (2000) 149-156.

[98] L. Heirmark, P. Shipkova, J. Greene, H. Munyyer, T. Yarosh-Tomaine, B. DiDomenico, R. Hare, B. Pramanik, J. Mass Spectrom. 37 (2002) 265-269.

[99] W. Kamm, F. Dionisi, C. Hischenhuber, H.-G. Schmarr, K.-H. Engel, Eur. J. Lipid Sci. Technol. 104 (2002) 756-761.

[100] Y.M. Choo, M.H. Ng, A.N. Ma, C.H. Chuah, M.A. Hashim, Lipids 40 (2005) 429-432.

[101] S. Taylor, J.W. King, J. Am. Oil Chem. Soc. 79 (2002) 1133-1136.

[102] G. Contarini, M. Povolo, E. Bonfitto, S. Berardi, Int. Dairy J. 12 (2002) 573-578.

[103] P. Kalo, T. Kuuranne, J. Chromatogr. A 935 (2001) 237-248.

[104] C.M. López Ortíz, M.S. Prats Moya, V. Berenguer Navarro, J. Food Compos. Anal. 19 (2006) 141-149.

[105] I. Mezine, H. Zhang, C. Macku, R.A.M. Lijana, J. Agric. Food Chem. 51 (2003) 5639-5646.

[106] W. Stöggl, C. Huck, S. Wongyai, H. Scherz, G. Bonn, J. Sep. Sci. 28 (2005) 1712-1718.

[107] J.J. Palmgrén, A. Töyräs, T. Mauriala, J. Mönkkönen, S. Auriola, J. Chromatogr. B 821 (2005) 144-152. 